\title{
Prevalence of psychiatric diagnoses in asylum seekers with follow-up
}

\author{
Kneginja Richter ${ }^{1,2,3^{*}}$, Lukas Peter ${ }^{1} \mathbb{B}$, Hartmut Lehfeld $^{1}$, Harald Zäske ${ }^{4}$, Salina Brar-Reissinger ${ }^{1}$ and Günter Niklewski ${ }^{1,2}$
}

\begin{abstract}
Background: In the study, the frequency and nature of asylum seekers' psychiatric diagnoses in a German admission center were examined. Additional aims were to identify changes in those diagnoses over time and to investigate health care utilization of mentally ill asylum seekers in the community.

Methods: The sample for the study "Psychiatric Examination of Asylum Seekers" in Bavaria consisted of a total of 283 asylum seekers and included 2 subsamples: help-seeking individuals and a randomly selected group. 34 of all asylum seekers were part of an extensive psychiatric follow-up examination (t2) about six months after the first examination (t1). Here, we used psychometric tools and a psychiatric interview by a medical doctor and a psychologist with the help of translators.
\end{abstract}

Results: $79 \%$ of help-seekers and $45 \%$ of the random group received at least one psychiatric diagnosis at $\mathrm{t} 1$. The most frequent diagnoses were trauma- and stress-related disorders, affective disorders, and insomnia. Men and Muslims were underrepresented in the help-seeking group. In the follow-up subsample, the rate of psychiatric diagnoses went down from $74 \%$ at t1 to $38 \%$ at t2. In contrast, the number of PTSD cases increased from 4 at t1 to 7 at t2. The severity of PTSD symptoms such as hyperarousal and avoidance also increased. Of the 13 persons in the follow-up-sample diagnosed with depression at $\mathrm{t} 1$, only 2 still fit the criteria of the disease at t2. Only 5 subjects had received some sort of psychotherapy or counseling.

Conclusion: The prevalence of mental illness in asylum seekers reported here corresponds to the usual range in the literature. It is significantly higher than in European civil society, especially regarding PTSD. At t2, the diagnoses of PTDS had increased within several months without evident additional traumatic events. Asylum seekers' psychiatric diagnoses soon after arrival should be recorded carefully and examination should be repeated after six months. The psychiatric and psychotherapeutic treatment of asylum seekers is still insufficient. Psychoeducative steps should be taken to relieve the stigma on mental illness, especially among males and Muslims.

Keywords: Asylum seekers, Refugees, Mental health, PTSD, Depression, Insomnia

\section{Background}

Asylum seekers are among the most vulnerable, marginalized and powerless groups in society with a high risk for psychiatric disturbances. They have most likely only recently fled difficult living conditions [1-8] and now live in constant fear of deportation and under permanent strain in admission centers, which contributes to their psychological distress.

\footnotetext{
* Correspondence: kneginja.richter@gmx.de

${ }^{1}$ Clinic Nuremberg, University Clinic for Psychiatry and Psychotherapy,

Paracelsus Private Medical University, Nuremberg, Germany

${ }^{2}$ Faculty for Social Sciences, Technical University for Applied Sciences Georg

Simon Ohm, Nuremberg, Germany

Full list of author information is available at the end of the article
}

Germany was the country with the highest number of applications for asylum $(65,000)$ within the European Union in the Year 2012, recording an increase of $41 \%$ in application numbers as compared to 2011 [9].

This study was conducted in one of Bavaria's biggest admission centers, the Admission Center for Asylum Seekers (ZAE) - Zirndorf. The goals were to examine asylum seekers' psychiatric diagnoses in the first weeks after their arrival in the country, to verify the diagnoses a few months after their discharge from the center and to examine whether mentally ill asylum seekers had received appropriate psychiatric and psychological treatment after discharge.

(c) The Author(s). 2018 Open Access This article is distributed under the terms of the Creative Commons Attribution 4.0 International License (http://creativecommons.org/licenses/by/4.0/), which permits unrestricted use, distribution, and 
Most studies on mental disorders in asylum seekers focus on posttraumatic stress disorder (PTSD), reporting a range of prevalence rates between 32 and 46\% [4, 1016]. Others report numbers as high as $74 \%$ [17] or as low as 14\% [18]. Affective and anxiety disorders were found to be the most frequent comorbidities with PTSD [19-21].

A review of published studies on the prevalence of mental disorders in asylum seekers shows a fundamental problem which makes a comparison of results difficult: the sampling methods used are very heterogeneous and led to samples that range from a randomly selected group of subjects to an examination of a rigidly selected group such as the population using counselling or other services [22].

Trying to build on and extend the reviewed research, we formulated the following questions: What are the prevalence rates of mental illness in groups of randomly selected and help-seeking asylum seekers? Which sociodemographic groups will be represented in these two groups? How will psychiatric diagnoses develop over time? And finally, in what ways will mentally ill asylum seekers receive treatment in the German public health system?

\section{Methods}

Within the project "Psychiatric Examination of Asylum Seekers" supported by the Bavarian Ministry of Labour, Social Affairs, Family and Women [23], a psychiatric center was installed in an admission center in southern Germany. Here, two samples of asylum seekers underwent examination for mental disorders in a preliminary study (t1) between 01/2011 and 05/2012. The first sample consisted of help-seekers, i.e. individuals who had contacted the center of their own impetus. Information regarding psychiatric services was freely available to the residents of the admission center in the form of flyers which had been translated into ten different languages. As a result of close working relationships with local services, medical practitioners, and volunteer services, the project coordinators were able to widely disseminate information about the psychiatric services offered. The random sample consisted of randomly selected residents of the center. As part of the randomization process, a cross-check procedure was used to ensure that no participants from the help seeking group were invited to the random group. All of the invited individuals agreed to participate in the initial screening and all participants provided their consent in written form. Following written agreement from the Ethical Committee, participants were interviewed within the first six weeks of their residence in the center. The most common countries of origin in both samples were Iran (30.4\%), Afghanistan (20.1\%), Russia (19.4\%), Iraq (14.5\%), and Azerbaijan
(5.7\%). Islam (66.5\%) and Christianity (13.9\%) were the most common religious denominations.

Participants were interviewed by trained bilingual specialists who administered questionnaires to assess the frequency of mental disorders in the 12 months before the interview. Where possible, patients' preferences with regard to the examiner's gender were accommodated. Diagnoses were made in accordance with the International Classification of Diseases, 10th revision (ICD 10; [24]) using the Mini-International Neuropsychiatric Interview (MINI; [25]). We assessed psychiatric symptoms by use of the Brief Symptom Inventory (BSI), a culturally sensitive 53-item self-report symptom checklist. Based on BSI results, nine primary symptom dimensions can be computed: somatic symptoms, obsessive-compulsive symptoms, feelings of personal inadequacy, depression, clinical anxiety, anger and hostility, phobic anxiety, paranoid ideation, and social alienation [26]. To measure suicidal thoughts, item 10 of the Montgomery Asberg Depression Rating Scale (MADRS) was used, explicitly asking on a seven point scale for the feeling that life is not worth living, death would be welcome, suicidal thoughts are present or that a suicidal act is being prepared [27]. PTSD symptoms were measured using the Essen Trauma Inventory (ETI), a screening inventory consisting of 35 items for a broad range of traumatic events and 23 symptom based items for posttraumatic stress symptoms on four subscales: intrusion, avoidance, hyperarousal, and peritraumatic dissociation [28]. To assess sleep disturbances, we used the Pittsburg Sleep Quality Index (PSQI), concentrating on the first three of its seven subscores, i.e. subjective sleep quality, sleep latency, and sleep duration [29]. In addition, the interview included questions about the asylum seekers' use of health services, as well as on social, economic and cultural factors since the migration.

The examinations were performed over a 3 -h period during which a psychiatric history was taken by a psychiatry specialist and psychometric testing was carried out by a psychologist. The psychologist/psychiatrist provided detailed information to the participants on the background of the study and the examination procedure. In all cases, the psychiatric-psychological examination was carried out fully after the person selected for examination had given their written consent.

One week after the first interview, subjects that had received a psychiatric diagnosis were asked to return for a second interview (see fig. 1). In this second consultation, therapeutic recommendations for future treatment were made after a discussion of the results and the diagnosis with the patient. Persons without a psychiatric diagnosis were not invited to the second interview.

Four to ten months later, after the asylum seekers had been discharged from the admission center to steadier 


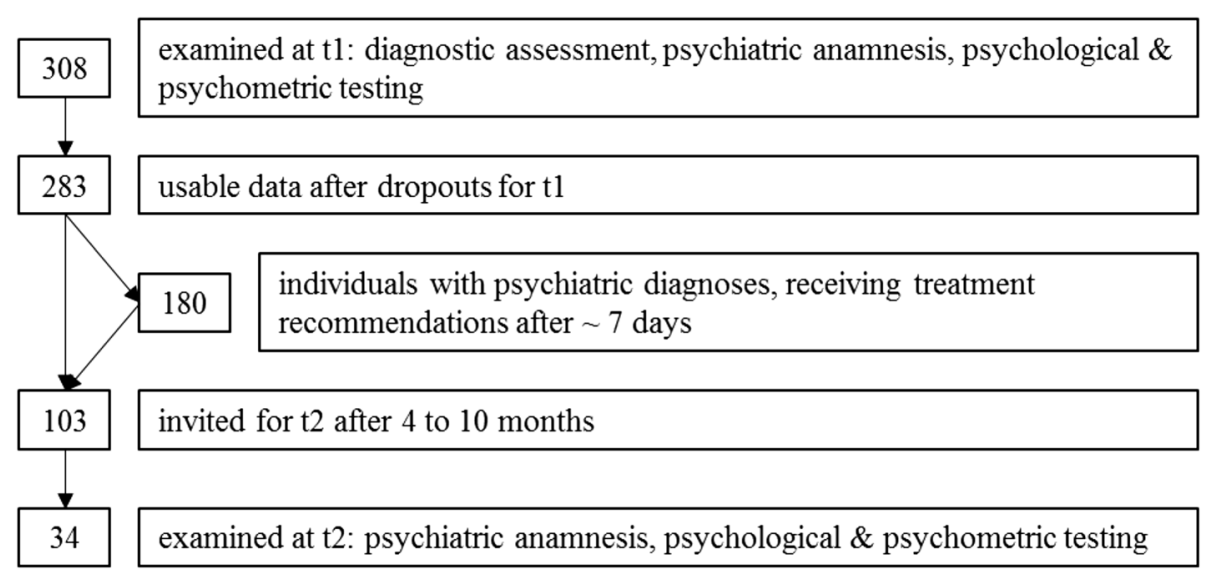

Fig. 1 Steps of examination

accommodations, a follow-up examination (t2) was carried out. Our aim was to interview subsamples of both initially examined groups in their new homes. At $\mathrm{t} 2$, most individuals in the sample were either of Iranian (44.1\%), Afghan (26.5\%), or Russian (11.8\%) nationality.

Statistical Analyses were performed using the program SPSS 20. Chi-square tests and variance analysis methods were used for interference statistical comparisons of the two subsamples in addition to the descriptive presentation of results by frequency charts and mean values. Missing data was excluded from the statistical analysis.

\section{Results}

\section{Preliminary examination ( $\mathbf{t} 1$ )}

In total, 308 individuals were examined. After dropouts, data for 283 asylum seekers (125 women, 158 men, age $31.9 \pm 10.6$ years) was analysed (see fig. 2 ). The most common reasons for dropout were fatigue or decompensation during the examination and refusal of the psychological examination after the psychiatric interview. 158 of the examined individuals were part of the help-seeking sample, 125 formed the random group.

Women $(51.9 \%$ vs. $34.4 \%$, Chi-square test $p<.01)$, Christians (22.4\% vs. $17.7 \%, p<.05)$, Russians $(27.8 \%$ vs $8.8 \%, p<.000)$ and Afghans $(24.1 \%$ vs. $15.2 \%, p<.000)$, as well as those with previous migration experience $(13.9 \%$ vs. $1.6 \%, p<.001)$ were significantly overrepresented in the help-seeking group as compared to the random group. We also found a tendency of those arriving with children prevailing among help-seekers $(55.1 \%$ vs. $44.8 \%, p=.088$ ), most likely because of the higher amount of women in this group. Men $(48.1 \%$ vs $65.5 \%$; $p<.01)$ and Muslims $(50.4 \%$ vs. $66.5 \% ; p<.05)$ were underrepresented among help-seekers. There were no significant differences regarding age, marital status, education, or professional status.

Significantly more psychiatric diagnoses were made in the help-seeking group than in the random group $(78.5 \%$

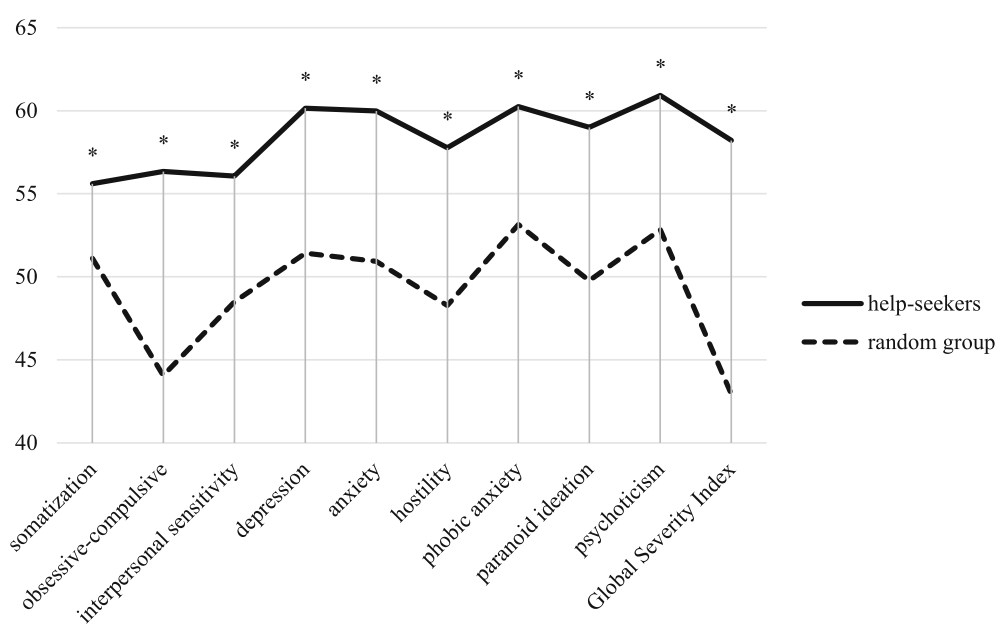

Fig. $2 \mathrm{BSI}$ profile plots for both groups at t1 (t-scores). $N=283$. All differences $p<.000$ 
vs. $44.8 \%, p<.000$, see Table 1$)$. The most common primary diagnoses were stress-related and anxiety disorders (F4 and F3; 53.3\% of diagnoses), affective disorders (34.4\%) and insomnia (7.2\%). There was no significant difference between the groups in the relative frequency of diagnoses (see Table 2). The most frequent diagnosis was PTSD with $17.6 \%$ of all subjects in the random group and $22.8 \%$ in the help seeking group fulfilling the criteria (see Table 1).

Help-seekers also showed significantly more psychiatric symptoms compared to the random group across all scales of the BSI (see fig. 2), as well as the MADRS, and the PSQI (ANOVA all $p<.000$ ). These differences persisted after excluding all individuals without a psychiatric diagnosis from the analysis. In external assessment, at least temporary thoughts of suicide were documented in $26 \%$ of the help-seeking group and in $6 \%$ of the random group $(p<.000)$. Likewise, the number of potentially traumatizing events in an individual's previous history reported in ETI was 1.1 in the random sample and almost double this number in the help-seeking group $(1.9, p<.000)$.

In the help-seeking group, $50.6 \%$ received a drug prescription from the psychiatrist as compared to $25.6 \%$ in the random group. Most of these prescriptions were for mild sedatives and antidepressants. 18 individuals were

Table 1 Frequencies of diagnose-clusters, including most frequent specific diagnoses, in both subsamples at t1

\begin{tabular}{cll}
\hline ICD 10 chapter & help seekers & random \\
\hline diagnosis & $124(78.5 \%)$ & $56(44.8 \%)$ \\
F0 & $1(0.6 \%)$ & $0(0.0 \%)$ \\
F1 & $1(0.6 \%)$ & $1(0.8 \%)$ \\
F2 & $2(1.3 \%)$ & $1(0.8 \%)$ \\
F3 & $46(29.1 \%)$ & $16(12.8 \%)$ \\
F32.1 & $14(8.9 \%)$ & $5(4.0 \%)$ \\
F33.1 & $9(5.7 \%)$ & $4(3.2 \%)$ \\
F33.2 & $12(7.6 \%)$ & $2(1.6 \%)$ \\
F4 & $65(41.1 \%)$ & $31(24.8 \%)$ \\
F43.1 & $36(22.8 \%)$ & $22(17.6 \%)$ \\
F43.2 & $14(8.9 \%)$ & $7(5.6 \%)$ \\
F5 & $8(5.1 \%)$ & $5(4.0 \%)$ \\
F6 & $1(0.6 \%)$ & $2(1.6 \%)$ \\
no diagnosis & $34(21.5 \%)$ & $69(55.2 \%)$ \\
total & $158(100 \%)$ & $125(100 \%)$ \\
\hline Note. F0 Oro & & M
\end{tabular}

Note. F0 = Organic, including symptomatic, mental disorders. F1 $=$ Mental and behavioural disorders due to psychoactive substance use. F2 = Schizophrenia, schizotypal and delusional disorders. F3= Mood (affective) disorders. F32.1 = Moderate depressive episode. F33.1 = Recurrent depressive disorder, current episode moderate. F33.2 = Recurrent depressive disorder, current episode severe without psychotic symptoms. F4 = Neurotic, stress-related and somatoform disorders. F43.1 = Posttraumatic stress disorder. F43.2 = Adjustment disorders. F5 = Behavioural syndromes associated with physiological disturbances and physical factors. F6 $=$ Disorders of adult personality and behavior
Table 2 Relative frequencies of F3 and F4 diagnoses in both subsamples at t1

\begin{tabular}{cll}
\hline psychiatric disorder & $\begin{array}{l}\text { help-seekers } \\
n=124\end{array}$ & $\begin{array}{l}\text { random } \\
n=56\end{array}$ \\
\hline F3 & $45(36.3 \%)$ & $16(28.6 \%)$ \\
F31.0 & $1(0.8 \%)$ & $0(0.0 \%)$ \\
F32.0 & $1(0.8 \%)$ & $3(5.4 \%)$ \\
F32.1 & $14(11.3 \%)$ & $5(8.9 \%)$ \\
F32.2 & $6(4.8 \%)$ & $1(1.8 \%)$ \\
F32.3 & $1(0.8 \%)$ & $0(0.0 \%)$ \\
F33.1 & $9(7.3 \%)$ & $4(7.1 \%)$ \\
F33.2 & $12(9.7 \%)$ & $2(3.6 \%)$ \\
F33.3 & $0(0 \%)$ & $1(1.8 \%)$ \\
F34.1 & $2(1.6 \%)$ & $0(0 \%)$ \\
F4 & $65(52.4 \%)$ & $31(55.4 \%)$ \\
F41.0 & $8(6.5 \%)$ & $1(1.8 \%)$ \\
F41.1 & $3(2.4 \%)$ & $0(0 \%)$ \\
F41.2 & $1(0.8 \%)$ & $1(1.8 \%)$ \\
F43.0 & $1(0.8 \%)$ & $0(0 \%)$ \\
F43.1 & $36(39.3 \%)$ & $22(29 \%)$ \\
F43.2 & $14(11.3 \%)$ & $7(12.5 \%)$ \\
F44.0 & $1(0.8 \%)$ & $0(0 \%)$ \\
F45.8 & $1(0.8 \%)$ & $0(0 \%)$ \\
\hline
\end{tabular}

Note. $\mathrm{F} 31.0=$ Bipolar affective disorder, current episode hypomanic. $\mathrm{F} 32.0=$ Mild depressive episode. F32.1 = Moderate depressive episode. F32.2 = Severe depressive episode without psychotic symptoms. F32.3 = Severe depressive episode with psychotic symptoms. F33.1 = Recurrent depressive disorder current episode moderate. F33.2 = Recurrent depressive disorder, current episode severe without psychotic symptoms. F33.3 = Recurrent depressive disorder, current episode severe with psychotic symptoms. F34.1 = Dysthymia. F41.0 = Panic disorder (episodic paroxysmal anxiety). F41.1 = Generalized anxiety disorder. F41.2 = Mixed anxiety and depressive disorder. F43.0 = Acute stress reaction. F43.1 $=$ Posttraumatic stress disorder. F43.2 = Adjustment disorders. F44.0 = Dissociative amnesia. F45.8 = Other somatoform disorders. F51.0 $=$ Nonorganic insomnia

referred to psychiatric inpatient treatment, 13 to psychiatric outpatient, and 18 to non-psychiatric outpatient treatment.

\section{Follow-up (t2)}

103 individuals were invited for a follow-up examination. For practical reasons, those that had moved away over $100 \mathrm{~km}$ from the study center in Nuremberg, Germany, were excluded from the follow-up. By the end of the study, 34 subjects (11 from the help-seeking group, 23 from the random group, age $32.50 \pm 11.14$ years) could be identified and examined. When controlling for group and gender, the follow-up sample did not differ significantly from the rest of the initial sample regarding symptoms on the BSI, MADRS or PSQI.

The average time lag between $\mathrm{t} 1$ and $\mathrm{t} 2$ was $214.6 \pm$ 86.4 days. There were no significant differences between former help seekers and members of the random group regarding sociodemographic characteristics. 
The total amount of psychiatric diagnoses decreased from 25 at $\mathrm{t} 1$ to 13 at $\mathrm{t} 2$. At $\mathrm{t} 1,41.2 \%$ had been diagnosed with an affective disorder from the F3 chapter of the ICD 10. At $\mathrm{t} 2,8.8 \%$ fit the criteria of such a disorder. All 7 cases of severe depressive episodes (F32.2, F33.2) had receded. Diagnoses of trauma and stress-related disorders stayed at $20.6 \%$ at both points in time. However, there was a shift, and arguably an increase, in severity: while there were four cases of adjustment disorder less, four new cases of PTSD were diagnosed (see Table 2). All three initial cases of non-organic insomnia either persisted or shifted to a more severe diagnose at follow-up.

More than half of the sample $(n=19)$ reported having been in contact with the public health system since t1, either receiving medical treatment (12), prescription drugs (2), psychotherapy (2), or other forms of therapy and counseling (3) (Table 3).

\section{Discussion}

Our results show a high prevalence of psychiatric disorders in asylum seekers with a significantly higher prevalence in the help-seeking group of patients as opposed to the random group. The most frequent primary diagnosis in both groups was PTSD (F43.1). Compared to the research provided by Wittchen and colleagues [30], the prevalence is clearly higher in our random sample than in the European population (17.6\% vs. $2.9 \%)$. This might be explained by the potentially traumatic circumstances that may have led this population to seek asylum in the first place, in combination with post migration stress [31-33]. The second most frequent diagnosis

Table 3 Overview of psychiatric diagnoses at t1 and t2 in the follow-up sample. $N=34$

\begin{tabular}{ccc}
\hline diagnosis & t1 & t2 \\
\hline F3 F32.1 & 14 & 3 \\
F32.2 & 4 & 1 \\
F33.1 & 3 & 0 \\
F33.2 & 3 & 1 \\
F34.1 & 4 & 0 \\
F4 & 0 & 1 \\
F43.1 & 7 & 7 \\
F43.2 & 3 & 7 \\
F51.0 & 4 & 0 \\
F60.8 & 3 & 3 \\
none & 1 & 0 \\
Note. 332. Modertedepressive episode. & 9 & 21
\end{tabular}

Note. F32.1 = Moderate depressive episode. F32.2 = Severe depressive episode without psychotic symptoms. F33.1 = Recurrent depressive disorder, current episode moderate. F33.2 = Recurrent depressive disorder, current episode severe without psychotic symptoms. F34.1 = Dysthymia. F43.1 = Posttraumatic stress disorder. F43.2 = Adjustment disorders. F51.0 = Nonorganic insomnia F60.8 other specific personality disorder found was a depressive episode (light to severe) followed by insomnia. When we combine the prevalence of stress-related and affective disorders, the results are similar to those shown in the research on refugees by Lindert and colleagues [5] (37.6\% vs. 40\%). In total, the prevalence rates in our random sample falls into the mid-range of values reported in literature on this topic $[4,12,14-16]$.

From the collected data we conclude that asylum seekers tend to be more vulnerable to psychiatric illness. This reflects the assumption by Lindert and colleagues [5] that within the heterogeneous group of migrants there is a higher prevalence of depression and anxiety in asylum seekers than in other groups, such as labor migrants.

From $\mathrm{t} 1$ to $\mathrm{t} 2$, the prevalence of PTSD increased without evident additional traumatic events. According to the diagnostic criteria for PTSD in ICD 10 [24], there is a time latency of several weeks or months for the manifestation of the main symptoms. These results suggest that asylum seekers' psychiatric diagnoses soon after arrival should be recorded carefully and that examination should be repeated after six months. Otherwise, PTSD symptoms might remain undiscovered and grow even more severe. Considering the diagnoses of depression, the disease receded in 11 of 13 cases. We assume that the improvement of social circumstances and living conditions after leaving the crowded admission center might be contributing to this, as only five subjects in the follow-up sample had received some sort of psychotherapy or counselling. The authors conclude that the psychological and psychiatric treatment of mentally ill asylum seekers after discharge from the admission center is insufficient.

The typical subjects in the help-seeking group were Russian women of Christian denomination with previous migration experience. In the random group, there was a higher proportion of male asylum seekers of Muslim denomination coming mainly from Iraq and Iran, of which $45 \%$ fulfilled the criteria for a psychiatric diagnosis. They, however, were not seeking help. The cause for this appears to be due to gender as well as cultural, ethnic and religious differences in how psychiatric symptoms are understood and ultimately expressed. Moreover, they could be a starting point for the targeted treatment of risk groups. In order for public health systems to cope with this problem, the authors suggest psychoeducation and information for asylum seekers with the aim to relieve stigmatization from mental illness.

\section{Implications}

From our perspective, a multi-professional and multilingual team with a background in cultural psychiatry is necessary to optimally diagnose and treat a population as 
heterogenous and burdened as asylum seekers. In the help-seeking group, $21.5 \%$ did not fulfill the criteria for a psychiatric illness. We assume that they may have suffered from psychological problems such as anxiety or sleep problems, but their symptoms were not distinct enough to fulfil the criteria for a psychiatric diagnosis. The second reason could be simulation of symptoms wishing to be granted asylum, which we can only assume. We believe, however, that by having two examiners (a psychiatrist and a psychologist) we were able to minimize false positives.

The diagnosis of recurrent depression (F33) was at 9.7\% of the random and $17 \%$ of the help-seeking group. This means that a high number of asylum seekers are likely to have suffered from depression in the past, which could impact on individual help-seeking behavior.

The fourth most frequent psychiatric diagnosis in our study was insomnia. In order to be able to make a difference between insomnia and insomnia symptoms, we asked for the severity of sleep difficulties. Usually, the subject reported that their insomnia bothered them much more than the depressive or anxious mood and that better sleep would also improve their mood [34]. Our experience was that for some asylum seekers words such as psychiatry, psychology, or stress were not familiar. However, asking how they slept opened the door for better understanding of their psychological status. For this reason, sleep could provide an effective avenue for treatment [35].

We did not diagnose an 'Enduring personality change after catastrophic experience' in any of the participants - one explanation for this fact was that not enough time had passed from the time of trauma.

Our final recommendation for further research on the evaluation of mental disorders in the population of asylum seekers is to always include a randomized control group - this is especially important to help gain representative data for this very diverse population.

\section{Limitations and weaknesses}

The random sample could have been structured differently so as to mirror the sociodemographic make-up of the residents at the ZAE Zirndorf more closely and to be more representative of this unit. At the same time, however, the high fluctuation of residents might have counteracted this approach. This means that the random sample only represents a snapshot of the situation at a given moment in time. A more long-term comparison including the statistics for the years 2011 and 2012 might provide further insights in this respect. What remains unclear is whether the site of interview had an impact on help seeking behavior because all of our interviews occurred onsite at the ZAE. Future studies should investigate help seeking behavior in other locations, such as hospitals. Finally, due to administrative and economic reasons, the follow-up group was a lot smaller than intended and may not have produced entirely representative results.

\section{Conclusions}

On the basis of current research, we recommend the establishment of outpatient psychiatric-psychological services for those who need treatment as well as short psychiatric screenings for all asylum seekers immediately upon their arrival in the host country. Screening and supportive consultation should be available as part of the first wave of medical screening/treatment with an option for pharmacotherapy if appropriate and necessary. Psychotherapeutic treatments could be offered as a second step in a hierarchy of treatment model. With regard to post migration stress, a helpful step would be to reduce the temporal duration of the application procedure for asylum status - this should also include limiting the time spent in an admission center.

\section{Abbreviations}

BSI: Brief Symptom Inventory; ETI: Essen Trauma Inventory; ICD

10: International Classification of Diseases, 10th revision; MADRS: Montgomery Asberg Depression Rating Scale; MINI: MiniInternational Neuropsychiatric Interview; PSQI: Pittsburg Sleep Quality Index; PTSD: Posttraumatic Stress Disorder; ZAE: Admission Center for Asylum Seekers ("Zentrale Aufnahmeeinrichtung")

\section{Funding}

This study was funded by the Bavarian State Ministry of Employment and Social Order, the Family and Women with the explicit aim to examine prevalence rates of mental illness and the demand for psychiatric care in the ZAE Zirndorf.

Availability of data and materials

The datasets used and/or analysed during the current study are available from the corresponding author on reasonable request.

\section{Authors' contributions}

$\mathrm{KR}, \mathrm{HL}, \mathrm{SBR}$, and $\mathrm{GN}$ were involved in designing and implementing the study. KR and LP wrote the manuscript. HL and $\mathrm{HZ}$ provided statistical evaluation and interpretation. All authors have revised the manuscript critically and have agreed to be accountable for all aspects of the work in ensuring that questions related to the accuracy or integrity of any part of the work are appropriately investigated and resolved.

Ethics approval and consent to participate

This study was approved by the ethics committee of the Bavarian State Medical Association. All participants provided written informed consent.

Consent for publication

Not applicable.

Competing interests

The authors declare that they have no competing interests.

\section{Publisher's Note}

Springer Nature remains neutral with regard to jurisdictional claims in published maps and institutional affiliations.

\section{Author details}

${ }^{1}$ Clinic Nuremberg, University Clinic for Psychiatry and Psychotherapy, Paracelsus Private Medical University, Nuremberg, Germany. ${ }^{2}$ Faculty for Social Sciences, Technical University for Applied Sciences Georg Simon Ohm, 
Nuremberg, Germany. ${ }^{3}$ Faculty for Medical Sciences, University Goce Delcev, Stip, Macedonia. ${ }^{4}$ Department of Psychiatry and Psychotherapy, Medical Faculty, Heinrich-Heine-University, Düsseldorf, Germany.

Received: 18 October 2017 Accepted: 12 June 2018

Published online: 20 June 2018

\section{References}

1. Abebe DS, Lien L, Hjelde KH. What we know and don't know about mental health problems among immigrants in Norway. J Immigr Minor Health. 2014;16:60-7.

2. Bhugra D. Migration and mental health. Acta Psychiatr Scand. 2004;109:243-58

3. Grüsser SM, Wölfling K, Mörsen CP, Albrecht U, Heinz A. Immigrationassociated variables and substance dependence. J Stud Alcohol Drugs. 2005:66:98-104.

4. Iversen VC, Morken G. Differences in acute psychiatric admissions between asylum seekers and refugees. Nord J Psychiatry. 2004;58:465-70.

5. Lindert J, Priebe S, Penka S, Napo F, Schouler-Ocak M, Heinz A. Depression and anxiety in labor migrants and refugees: a systematic review and metaanalysis. Soc Sci Med. 2009;69:246-57.

6. Machleidt W, Calliess IT. Transkulturelle Psychiatrie und Migration: Psychische Erkrankungen aus ethnischer Sicht. Psychiatrie (Stuttg). 2005;2:77-84.

7. Ryan DA, Kelly FE, Kelly BD. Mental health among persons awaiting an asylum outcome in western countries. Int J Ment Health. 2009:38:88-111.

8. Tribe R. Mental health of refugees and asylum-seekers. Adv Psychiatr Treat 2002:8:240-7.

9. Bundesamt für Migration und Flüchtlinge. Migrationsbericht 2012. 2014. http://www.bamf.de/SharedDocs/Anlagen/DE/Publikationen/ Migrationsberichte/migrationsbericht-2012.pdf. Accessed 23 Aug 2017.

10. Gäbel U, Ruf M, Schauer M, Odenwald M, Neuner F. Prävalenz der posttraumatischen Belastungsstörung (PTSD) und Möglichkeiten der Ermittlung in der Asylverfahrenspraxis. Z Klin Psychol Psychother. 2006;35:12-20.

11. Gerritsen AA, Bramsen I, Devillé W, van Willigen LH, Hovens JE, Van Der Ploeg HM. Physical and mental health of afghan, Iranian and Somali asylum seekers and refugees living in the Netherlands. Soc Psychiatry Psychiatr Epidemiol. 2005;66:98-104.

12. Karunakara UK, Neuner F, Schauer M, Singh K, Hill K, Elbert T, Burnham G. Traumatic events and symptoms of post-traumatic stress disorder amongst Sudanese nationals, refugees and Ugandans in the West Nile. Afr Health Sci. 2004:4:82-93.

13. Laban CJ, Gernaat HB, Komproe IH, Schreuders BA, de JJT. Impact of a long asylum procedure on the prevalence of psychiatric disorders in Iraqi asylum seekers in the Netherlands. J Nerv Ment Dis. 2004;192:843-51.

14. Peltzer K. Trauma and mental health problems of Sudanese refugees in Uganda. Cent Afr J Med. 1999;45:110-4.

15. Roodenrijs T, Scherpenzeel R, de Jong J. Traumatic experiences and psychopathology among Somalian refugees in the Netherlands. Tijdschrift voor Psychiatrie. 1998:40:132-42.

16. Silove D, Sinnerbrink I, Field A, Manicavasagar V, Steel Z. Anxiety, depression and PTSD in asylum-seekers: assocations with pre-migration trauma and post-migration stressors. Br J Psychiatry. 1997;170:351-7.

17. Sieberer M, Ziegenbein M, Eckhardt G, Machleidt W, Calliess IT. Psychiatrische Begutachtung im Asylverfahren. Psychiatr Prax. 2011;38:38-44.

18. Bradley $L$, Tawfiq N. The physical and psychological effects of torture in Kurds seeking asylum in the United Kingdom. Torture. 2006;16:41-7.

19. Bogic M, Njoku A, Priebe S. Long-term mental health of war-refugees: a systematic literature review. BMC Int Health Hum Rights. 2015;15:29. https:/ doi.org/10.1186/s12914-015-0064-9.

20. Breslau N, Davis GC, Schultz LR. Posttraumatic stress disorder and the incidence of nicotine, alcohol, and other drug disorders in persons who have experienced trauma. Arch Gen Psychiatry. 2003;60:289-94.

21. Ehlers A, Steil R, Winter H, Foa EB. German translation of the posttraumatic stress diagnostic scale (PDS): unpublished manuscript; 1996.

22. Schwarz-Nielsen $\mathrm{KH}$, Elklit A. An evaluation of the mental status of rejected asylum seekers in two Danish asylum centers. Torture. 2009;19:51-9.

23. Richter K, Lehfeld H, Niklewski G. Warten auf Asyl: Psychiatrische Diagnosen in der zentralen Aufnahmeeinrichtung in Bayern. Gesundheitswesen. 2015; 77:834-8.

24. World Health Organization. The ICD-10 classification of mental and behavioural disorders: clinical descriptions and diagnostic guidelines. Geneva: World Health Organization; 1992.
25. Hergueta T, Baker R, Dunbar GC. The MINI-international neuropsychiatric interview (MINI): the development and validation of a structured diagnostic psychiatric interview for DSM-IV and ICD-10. J Clin Psychiatry. 1998;59(Suppl 20):2233.

26. Derogatis LR, Spencer PM. Brief symptom inventory: BSI. Upper Saddle River, NJ: Pearson; 1993

27. Montgomery SA, Asberg M. A new depression scale designed to be sensitive to change. Br J Psychiatry. 1979;134:382-9.

28. Tagay S, Erim Y, Möllering A, Stoelk B, Mewes R, Senf W. Das Essener Trauma-Inventar (ETI): Ein Screeninginstrument zur Identifikation traumatischer Ereignisse und posttraumatischer Störungen. Psychother Psychosom Med Psychol. 2006;56:A98

29. Buysse DJ, Reynolds CF, Monk TH, Berman SR, Kupfer DJ. The Pittsburgh sleep quality index: a new instrument for psychiatric practice and research. Psychiatry Res. 1989:28:193-213.

30. Wittchen HU, Jacobi F, Rehm J, Gustavsson A, Svensson M, Jönsson B, et al. The size and burden of mental disorders and other disorders of the brain in Europe 2010. Eur Neuropsychopharmacol. 2011;21:655-79. https://doi.org/ 10.1016/j.euroneuro.2011.07.018.

31. Heeren M, Mueller J, Ehlert U, Schnyder U, Copiery N, Maier T. Mental health of asylum seekers: a cross-sectional study of psychiatric disorders. BMC Psychiatry. 2012:12:114. https://doi.org/10.1186/1471-244X-12-114.

32. Silove D, Steel Z, McGorry P, Mohan P. Trauma exposure, postmigration stressors, and symptoms of anxiety, depression and post-traumatic stress in Tamil asylum-seekers: comparison with refugees and immigrants. Acta Psychiatr Scand. 1998:97:175-81.

33. Sönmez E, Jesuthasan J, Abels I, Nassar R, Kurmeyer C, Schouler-Ocak M Study on female refugees - a representative research study on refugee women in Germany. European Psychiatry. 2017;41:S251. https://doi.org/10 1016/j.eurpsy.2017.02.038.

34. Ohayon MM, Reynolds CF. Epidemiological and clinical relevance of insomnia diagnosis algorithms according to the DSM-IV and the international classification of sleep disorders (ICSD). Sleep Med. 2009:10:95260. https://doi.org/10.1016/j.sleep.2009.07.008.

35. Bronstein I, Montgomery P. Sleeping patterns of afghan unaccompanied asylum-seeking adolescents: a large observational study. PLoS One. 2013;8: 56156. https://doi.org/10.1371/journal.pone.0056156.

Ready to submit your research? Choose BMC and benefit from

- fast, convenient online submission

- thorough peer review by experienced researchers in your field

- rapid publication on acceptance

- support for research data, including large and complex data types

- gold Open Access which fosters wider collaboration and increased citations

- maximum visibility for your research: over $100 \mathrm{M}$ website views per year

At BMC, research is always in progress.

Learn more biomedcentral.com/submissions 